\title{
Amphetamine-Induced Place Preference and Conditioned Motor Sensitization Requires Activation of Tyrosine Kinase Receptors in the Hippocampus
}

\author{
Fei Shen, ${ }^{1}$ Gloria E. Meredith, ${ }^{2}$ and T. Celeste Napier ${ }^{1}$ \\ ${ }^{1}$ Neuroscience Program and Department of Pharmacology and Experimental Therapeutics, Loyola University Chicago Medical Center, Maywood, Illinois \\ 60153, and ${ }^{2}$ Department of Cellular and Molecular Pharmacology, Chicago Medical School, Rosalind Franklin University of Medicine and Science, North \\ Chicago, Illinois 60064
}

\begin{abstract}
The environmental context in which abused drugs are taken contribute to the drug experience and is a powerful and persistent stimulus to elicit memories of that experience even in the abstinent addict. Using amphetamine (AMPH) as the unconditioned stimulus, the present study compared two popular context-dependent paradigms in rats, conditioned motor sensitization (CMS) and conditioned place preference (CPP), to ascertain whether particular brain regions were differentially involved. The neuronal substrates underlying these context-dependent behaviors are poorly understood, but regulators of the neuronal plasticity that accompany learning, such as neurotrophic factors and their cognate tyrosine kinase receptors (e.g., TrkB), are credible candidates. We found a significant elevation of TrkB-like immunoreactivity specifically in CA3/dentate gyrus (DG) subregions of the hippocampus after AMPH (0.3 mg/kg)-induced CPP, but not in the delayed-paired (control) AMPH condition. A higher AMPH dose $(1.0 \mathrm{mg} / \mathrm{kg})$ induced both CPP and CMS and elevated TrkB in the CA3/DG as well as in the nucleus accumbens shell. The development of both conditioned behaviors was blocked by intraCA3/DG infusion of the Trk inhibitor K-252a. These findings reveal that CPP and CMS are induced by different doses of AMPH and are associated with TrkB changes in particular brain regions. Moreover, Trk receptors in the hippocampus are critical mediators of the neuronal changes necessary for inducing both forms of conditioning. Thus, although these two conditioning models are distinct, because they are commonly regulated by the hippocampal Trk system, these receptors may be a therapeutic target for attenuating the significance of contextual cues that otherwise strengthen the addictive properties of abused drugs.
\end{abstract}

Key words: rat; TrkB; BDNF; psychostimulant; associative learning; behavioral sensitization

\section{Introduction}

Psychostimulants such as amphetamine (AMPH) increase monoamine transmission, thus initiating a cascade of cellular events that in turn modifies behavior. When AMPH administration is repeatedly associated with a distinct environment, the environment serves as a cue and can elicit positive subjective feelings even in the absence of drug. AMPH-induced associative learning is maladaptive, and once consolidated, these drugassociated memories contribute to the difficulty of current treatments to prevent relapse in the drug-withdrawn addict. Thus, the advent of efficacious therapies for addiction requires understanding the brain events that are involved in drug-induced associative learning.

\section{Received Feb. 19, 2006; revised Aug. 19, 2006; accepted Aug. 20, 2006.}

This work was supported by United States Public Health Service Grants DA016662 and DA019763. F.S. was also supported by Loyola University Chicago Graduate School. We appreciate Dr. Beatrix Kovacs for her excellent technical assistance; Drs. Edward Neafsey, Jim Sinacore, and Thomas Green for their valuable statistical advice; and Dr. David Rademacher, Rob Coon, and Robin Voigt for their helpful comments on previous drafts of this manuscript.

Correspondence should be addressed to Fei Shen, Department of Pharmacology and Experimental Therapeutics, Building 102, Room 3639, Loyola University Chicago Medical Center, 2160 South 1st Avenue, Maywood, IL 60153. E-mail: fshen@lumc.edu.

T.C. Napier's present address: Department of Pharmacology, Rush University Medical Center, Chicago, IL 60612. D0I:10.1523/JNEUROSCI.2898-06.2006

Copyright $\odot 2006$ Society for Neuroscience $\quad$ 0270-6474/06/2611041-11\$15.00/0
$\mathrm{AMPH}$-induced conditioned place preference (CPP) in rats is a popular model of drug-mediated associative learning in humans. Conditioned rats demonstrate a preference for the environment previously paired with $\mathrm{AMPH}$ in a drug-free state (Sherman et al., 1980; Bardo and Bevins, 2000). Repeated intermittent exposure to AMPH, such as that used for CPP, also produces a progressive enhancement of motor behavior (Segal and Mandell, 1974). In rats not previously habituated to the test environment, repeated exposure to drug can induce motor activity that reflects unconditioned, drug-induced, and conditioned environmental context-elicited responses (Vezina and Stewart, 1984; Gold et al., 1988; Anagnostaras and Robinson, 1996). Many aspects of CPP and conditioned motor sensitization (CMS) seem to overlap (Robinson et al., 1998); however, comonitoring these psychostimulant-induced behaviors in the same rat reveals impressive distinctions (Hemby et al., 1992; Olmstead and Franklin, 1994), suggesting different neural substrates are involved in the two conditioned behaviors. These insightful evaluations illustrate that enhanced understanding of the selective substrate(s) underlying these two behaviors induced by repeated AMPH exposure can be gained by concurrent assessment of CPP and CMS, and this approach was used here.

Neurotrophic factors are critical mediators of neuroplasticity 
(Thoenen, 1995), long-term potentiation (LTP) (Yamada et al., 2002), and a number of mnemonic tasks (Figurov et al., 1996; Dragunow et al., 1997). Brain-derived neurotrophic factor (BDNF), by activating its cognate tyrosine kinase B (TrkB) receptors, can induce morphological changes in neurons including synaptogenesis (Lu et al., 2002), spine creation, and dendritic growth (McAllister et al., 1999). These adaptations increase synaptic strength to promote neuronal processes that are thought to underlie learning and memory (Geinisman, 2000; Geinisman et al., 2000), psychostimulant-induced behavioral sensitization (Horger et al., 1999), and drug-seeking behavior (Grimm et al., 2003; Lu et al., 2004).

The hippocampus is required for many aspects of mnemonic processes in both humans and animals (Milner and Penfield, 1955; Milner et al., 1998) and may contribute to the increase in incentive salience that drugs of abuse acquire after repeated exposure (Winocur et al., 1987; Kilts et al., 2001; Meyers et al., 2003). The present study was designed to investigate whether (1) AMPH-induced CPP can facilitate TrkB expression in the hippocampus, (2) CMS and/or CPP engage the hippocampus, and (3) Trk receptors in the hippocampus are critical mediators for both AMPH-induced CPP and CMS.

\section{Materials and Methods \\ Animals}

Male Sprague Dawley rats weighing 280-320 g (Harlan, Indianapolis, IN) were housed in environmentally controlled conditions (12 h light/ dark cycle: 7:00 A.M. light/7:00 P.M. dark, with temperature maintained at $23-25^{\circ} \mathrm{C}$ ) with continuous access to rat chow and water. The rats were housed in pairs, except for those rats implanted with intracerebral cannulas, which were housed individually after implantation surgery. The rats were acclimated to colony conditions for at least 1 week before any experimentation or surgery. All animals were handled in accordance with the procedures established in the Guide for the Care and Use of Laboratory Animals (National Research Council, Washington, DC). The specific protocols were approved by the Loyola University Medical Center Institutional Animal Care and Use Committee.

\section{Apparatus for monitoring rat behavior}

The behavioral-monitoring box used for CPP and CMS $(63 \times 30 \times 30$ $\mathrm{cm}$; AccuScan Instruments, Columbus, $\mathrm{OH}$ ) was divided into three chambers by two removable guillotine doors, with square-shaped left and right chambers connected by a smaller rectangular center chamber. The left and right chambers contained vertical or horizontal stripes on the wall and distinct floor textures. Motor activity and time spent in each chamber were recorded simultaneously by two banks of photobeams (VersaMax software; AccuScan Instruments).

\section{Drugs}

D-Amphetamine-sulfate (Sigma-Aldrich, St. Louis, MO) was dissolved in sterile $0.9 \%$ saline, and the doses $(0.3$ or $1.0 \mathrm{mg} / \mathrm{ml} / \mathrm{kg}$ ) were calculated as the salt. The tyrosine kinase inhibitor K-252a (Calbiochem, La Jolla, CA) was dissolved in $25 \% \mathrm{DMSO} / \mathrm{saline}$ to a final concentration $25 \mathrm{ng} / 0.5 \mu \mathrm{l}$ (Tapley et al., 1992; Rattiner et al., 2004) and stored in aliquots at $-20^{\circ} \mathrm{C}$ in the dark.

\section{Treatment and behavioral testing procedures}

One hundred forty rats were pretested at least $48 \mathrm{~h}$ before initiating the conditioning sessions for unconditioned preference. During the $15 \mathrm{~min}$ pretest session, rats were allowed to explore the entire apparatus, and those that did not spend $>70 \%$ of the time in one chamber $(n=136)$ were included in the study. These rats were randomly assigned to three conditioning treatments: (1) AMPH, (2) saline, and (3) AMPH delayed pairing. Within each drug treatment group, the drug-paired chamber was assigned in a counterbalanced order, with some individuals assigned to their pretest "more time spent" side, whereas others were assigned to their pretest "less time spent" side; thus, the average time spent for each group in the drug-paired and saline-paired side were approximately equal before conditioning. The treatment protocols were as follows.

\section{$A M P H$}

Group A. Rats received an intraperitoneal injection of $0.3 \mathrm{mg} / \mathrm{ml} / \mathrm{kg}(n=$ 16) or $1.0 \mathrm{mg} / \mathrm{ml} / \mathrm{kg}(n=24)$ AMPH on days 1,3 , and 5 immediately before being confined to one side of the activity box (drug-paired side) for $45 \mathrm{~min}$ and returned to their home cage. On days 2 and 4, the rats received an intraperitoneal injection of saline $(1 \mathrm{ml} / \mathrm{kg}$ ) before placement in the opposite side for $45 \mathrm{~min}$ (saline-paired side) and were returned to their home cage. Motor activity was recorded during each 45 min conditioning period.

Group B. Repeated intermittent injections of AMPH are known to progressively enhance motor responses [i.e., sensitization (Segal and Mandell, 1974)]. We sought to determine whether motor sensitization was obtained with the present paradigm and, if so, whether it was context dependent. To that end, rats were conditioned with $1.0 \mathrm{mg} / \mathrm{kg}$ AMPH on days 1 and 3 with one side of the CPP box and with saline on days 2 and 4 with the opposite side. On the fifth day, immediately after the intraperitoneal $1.0 \mathrm{mg} / \mathrm{kg}$ AMPH injection, one set of rats $(n=7)$ was confined to the previously AMPH-paired side, whereas the other set $(n=8)$ was confined in the side previously paired with saline, and motor activity was measured for $45 \mathrm{~min}$.

\section{Saline}

Rats in the saline (i.e., vehicle) control group $(n=24)$ received $1 \mathrm{ml} / \mathrm{kg}$ saline intraperitoneally and were immediately confined to one side of the activity box on days 1, 3, and 5 (considered "drug-paired side") and confined to the opposite side on days 2 and 4 (saline-paired side) for 45 min for 5 consecutive days.

\section{AMPH delayed pairing}

To distinguish the effects of drug-induced learning from the effects of drug exposure alone, we tested a set of rats $(n=8)$ that received AMPH as above, but the time interval between the unconditioned stimulus (UCS; i.e., AMPH) and the conditioned stimulus (CS; the environmental context) was lengthened to $4 \mathrm{~h}$ so that no association could be made between the drug effect and the environment. Four hours was selected because this is sufficient for this dose of intraperitoneal AMPH to be mostly cleared from the rat brain (Honecker and Coper, 1975). Accordingly, rats received $1 \mathrm{mg} / \mathrm{kg}$ AMPH intraperitoneally and were returned to their home cage for $4 \mathrm{~h}$ before being confined for $45 \mathrm{~min}$ to one side of the activity box on days 1, 3 and 5 and to the opposite side after saline injection on days 2 and 4 .

Three days $(\sim 72 \mathrm{~h}$ ) after the last injection, all rats were habituated to the test room for $1 \mathrm{~h}$, after which time, drug-free rats were placed in the center of the activity box while the two guillotine doors were in the down position. Both doors were removed allowing the rats to freely move throughout the box for $30 \mathrm{~min}$. The amount of time spent in each chamber was tallied.

\section{Immunohistochemistry}

Immunohistochemistry (IH) was performed at day 9 ( $1 \mathrm{~d}$ after the CPP test and $\sim 96 \mathrm{~h}$ after the last AMPH injection). Using the same treatment and behavioral paradigm in a separate group of rats $(n=20)$, the CPP expression induced by $0.3 \mathrm{mg} / \mathrm{kg}$ AMPH was determine to persist at least to day $10(1005 \pm 51 \mathrm{~s}$ in the drug-paired side vs $562 \pm 49 \mathrm{~s}$ in the saline-paired side; paired $t$ test, $p=0.0003$ ). Twenty (11 AMPHconditioned, 4 delayed-pairing, and 5 saline-treated) rats were perfused for IH evaluations. The behavior of these rats met two criteria: (1) for CMS, day 5 motor scores after $1 \mathrm{mg} / \mathrm{kg}$ AMPH had to be greater than those on day 1; and (2) for CPP (0.3 and $1.0 \mathrm{mg} / \mathrm{kg} \mathrm{AMPH})$, the CPP scores (described in the legend to Fig. 1) were rank ordered, and rats with the top $50 \%$ were perfused. It is important to note that the score difference was minor, because the CPP score of the AMPH-treated perfused rats $(n=11)$ was $149 \pm 31 \mathrm{~s}$ (SEM) and not statistically different from the nonperfused rats $(91 \pm 16 s ; n=29 ; p>0.05)$. To perfuse, the rats were deeply anesthetized with chloral hydrate $(400 \mathrm{mg} / \mathrm{kg}$, i.p.), and transcar- 
dial perfusion of cold saline followed by $4 \%$ paraformaldehyde in $0.1 \mathrm{M}$ phosphate buffer (PB), pH 7.4, was used. Brains were postfixed in the same fixative for $120 \mathrm{~min}$, allowed to sink in gradient sucrose in $\mathrm{PB}$, and cut in $40 \mu \mathrm{m}$ coronal sections on a freezing microtome. Sections were immunoreacted, free floating, in rabbit anti-TrkB (Santa Cruz Biotechnology, Santa Cruz, CA) diluted 1:400 in $0.1 \mathrm{M}$ PBS containing $0.2 \%$ Triton X-100 for $24 \mathrm{~h}$ at $4^{\circ} \mathrm{C}$. The reaction was developed using the appropriate secondary antiserum and an avidin-biotin-peroxidase incubation (Elite kit; Vector Laboratories, Burlingame, CA) and revealed using $0.05 \%$ 3'-3-diaminobenzidine hydrochloride (Sigma, St. Louis, $\mathrm{MO}$ ) and $0.01 \% \mathrm{H}_{2} \mathrm{O}_{2}$. Brain sections were then mounted on slides and coverslipped. The IH for all treatment groups was performed at the same time.

Three different controls were performed before IH staining to demonstrate that the antibody was TrkB specific: TrkB blocking peptide was mixed with primary antiserum, the primary antiserum was omitted, or sections were incubated in normal rabbit IgG. TrkB staining was absent after all three control procedures (data not shown). Moreover, the staining pattern produced in the current study with the TrkB antibody (Santa Cruz Biotechnology) was very similar to that reported by Yan et al. (1997) using antibodies raised on site.

To quantify the optical density of TrkB staining, the treatment groups for all slides were blind coded, and selective brain regions were qualitatively surveyed by two treatment-"blind" observers. Regions that demonstrated staining (regardless of treatment group) were digitally captured using an Olympus AH-2 microscope and DP-11 digital camera system (Olympus America, Melville, NY). To remove light-intensity variation in the microscope field and tissue background, for each image a negative control (primary omit) coverslipped tissue at the similar location was imaged, and this image was digitally subtracted from a photomicrograph of interest using image analysis software (Scion Image; Scion, Frederick, MD). The image was quantified as an integrated density score (mean density $\times$ the number of labeled pixels in the region) (Wang and McGinty, 1995; Zhou et al., 2004). The integrated density for three consecutive sections at different levels [CA1, CA3, dentate gyrus (DG), and basolateral amygdala (blA): bregma, -2.8 and $-4.1 \mathrm{~mm}$ average; shell and core of nucleus accumbens (NAc): bregma, +1.6 $\mathrm{mm}$; ventral pallidum (VP): bregma, $-0.4 \mathrm{~mm}$ ] was measured and averaged in each rat.

\section{In situ hybridization}

In situ hybridization assays were conducted on hippocampal sections taken from six rats showing CPP after AMPH conditioning $(1.0 \mathrm{mg} / \mathrm{kg}$, i.p.) and six rats conditioned only with saline. Two hours after the CPP test, rats were anesthetized with pentobarbital ( $75 \mathrm{mg} / \mathrm{kg}$, i.p.) and immediately decapitated. The brains were removed, immediately frozen in isopentane on dry ice, and stored at $-70^{\circ} \mathrm{C}$ until they were cut in $12 \mu \mathrm{m}$ sections using a cyostat/microtome. Sections were dry mounted onto poly-L-lysine-coated slides, fixed ( $4 \%$ paraformaldehyde), defatted, and pretreated before being hybridized. An oligonucleotide probe (34 mer, complementary to nucleotides 2214-2247; GenBank accession number M55291; Invitrogen, Rockville, MD) was used to detect rat full-length TrkB cDNA. The probe was radiolabeled at the $3^{\prime}$ end using $\left[\alpha^{-{ }^{35}} \mathrm{~S}\right]$ deoxyadenosine triphosphate $(1250 \mathrm{Ci} / \mathrm{mmol}$; PerkinElmer, Boston, MA) and terminal deoxynucleotidyl transferase to a specific activity of $8-10 \times 10^{5} \mathrm{cpm} / \mu \mathrm{l}$ (Meredith et al., 2002). Slides were incubated overnight at $37^{\circ} \mathrm{C}$ in a humidified chamber and apposed to Kodak (Rochester, NY) Bio-max film for $10 \mathrm{~d}$ at $4^{\circ} \mathrm{C}$.

Gene expression in the DG was assessed. All measurements were made using NIH Image (Scion, Rockville, MD). Films were captured using a light table (Northern Light; Imaging Research, Ontario, Canada) and a video camera. For each animal, optical density measurements from two to three sections were obtained and averaged. A white-matter reading was subtracted from each of the gray values recorded as background correction. The measurements were averaged for each animal and expressed as the percentage of controls.

\section{Surgical procedures for intracerebral implantation of guide cannulas}

Procedures followed those described in previous reports from the Napier laboratory (Napier and Chrobak, 1992). In brief, after 1 week of acclimation to the Loyola vivarium, 48 rats were anesthetized with pentobarbital (50 mg/kg, i.p.) and placed in a Kopf Instruments (Tujunga, CA) stereotaxic frame. After the skull was exposed, guide cannulas (23 gauge; Legg Plastic Products, Roanoke, VA) were lowered bilaterally into the hippocampus ( $3.0 \mathrm{~mm}$ posterior to bregma, $1.6 \mathrm{~mm}$ lateral to midline, and $2.4 \mathrm{~mm}$ ventral to skull, which is $1.3 \mathrm{~mm}$ above the DG/CA3 target). For placement controls, cannulas were implanted dorsal to these stereotaxic coordinates ( $3.0 \mathrm{~mm}$ posterior to bregma, $1.6 \mathrm{~mm}$ lateral to midline, and $1.5 \mathrm{~mm}$ ventral to skull, which is $0.5 \mathrm{~mm}$ above the cortical target). Stainless steel mounting screws and dental acrylic were used to fix the cannulas to the skull. The skin incision was closed with sutures, and antibiotic ointment was applied. A dummy injector (30 gauge, which did not extend below the tip of the implanted cannulas) was inserted into each cannula. One-week recovery was allowed between the surgery and behavioral training.

\section{Intracerebral microinjection}

During the last $3 \mathrm{~d}$ of the recovery period, the rats were acclimated to the intracerebral injection procedures as follows. The dummy injectors were removed, and 30 gauge sham injectors were inserted into the implanted cannulas (but did not extend below the implanted cannulas tips) and left in place for $6 \mathrm{~min}$. The sham injectors then were removed, dummy injectors reinserted, and the rats were returned to their home cage. For intracerebral injection, the injectors extended $1.3 \mathrm{~mm}$ below the hippocampal cannula tips and $0.5 \mathrm{~mm}$ below the cortical cannula tips. The opposite end of the injectors was connected to $10 \mu$ l Hamilton (Reno, NV) syringes via PE10 polyethylene tubing (Becton Dickinson, Franklin Lakes, NJ); the syringes were placed in CMA infusion pumps (Carnegie Medicine, Stockholm, Sweden) set to deliver fluid at a rate of $0.1 \mu \mathrm{l} / \mathrm{min}$. A total volume of $0.5 \mu \mathrm{l}$ was delivered per side. One minute later (to allow for diffusion of the drug away from the injector tip), the injectors were removed and dummy injectors were replaced; the intraperitoneal injection was immediately administered (AMPH or saline), and the rats were placed into the activity box. On AMPH-conditioning days (days 1, 3, and 5 ), the tyrosine kinase inhibitor K-252a ( $25 \mathrm{ng} / 0.5 \mu \mathrm{l}$ of $25 \% \mathrm{DMSO} /$ saline per side) or the vehicle alone ( $0.5 \mu \mathrm{l}$ of $25 \%$ DMSO in $0.9 \%$ sterile saline per side) was bilaterally injected into the hippocampus (or cortex for the placement controls). Sham injections were given on saline-paired days (days 2 and 4). A sham intracerebral injection also was given immediately before CPP test on day 8 , and the test time was $30 \mathrm{~min}$.

\section{Verification for cannulation site}

After the completion of behavioral testing, rats were deeply anesthetized with chloral hydrate $(400 \mathrm{mg} / \mathrm{kg}$, i.p.). The brains were removed, fresh frozen using dry ice, and cut in $60 \mu \mathrm{m}$ coronal sections. Sections mounted on subbed slides were stained with cresyl violet. The intracerebral infusion site (marked by lesion produced by injector) was agreed on by two treatment-blind observers using light microscopy and reconstructed onto a rat stereotaxic brain map (see Fig. 3).

\section{Statistical analysis}

The effect of AMPH on motor activity was determined by two-way repeated-measures of ANOVA, followed by post hoc Newman-Keuls multiple comparisons tests (Table 1). To directly compare dose effects for repeated AMPH-induced behaviors between CMS and CPP, the behavioral scores were standardized (detailed in the legend to Fig. 1) and zero was set as a theoretical mean (see Fig. 1B). Statistical evaluations were conducted using a two-tailed one-sample $t$ test with the Bonferroni adjustment (i.e., the $\alpha$ of 0.05 was divided by the number of treatments; see the legend to Fig. 1). To track behavioral responses of individual rats, paired $t$ tests were used to compare the first (day 1 ) and last (day 5) day of conditioning for motor score, as well as drug-paired side versus salinepaired side for CPP score; the Bonferroni adjustment was performed when appropriate (refer to the legends to Figs. 4 and 5). Data from IH 
(see Fig. 2; Table 2) were analyzed by one-way ANOVA, followed by post hoc comparisons (Newman-Keuls test). Data from in situ hybridization were assessed by comparing the two treatment groups via a Student's $t$ test. A priori set (planned) contrasts were evaluated in those cases in which multiple data sets were collected within each treatment group for several different treatments (Table 3). Except when Bonferroni adjustment was used, the $\alpha$ level was set at $p<0.05$. Data are presented as the sample mean \pm SEM.

\section{Results \\ AMPH-induced motor sensitization \\ Group A: development}

As reported previously (Browman et al., 1998), our data showed that a single injection of 0.3 or $1.0 \mathrm{mg} / \mathrm{kg}$ AMPH produced a dose-related increase in locomotor activity (Table 1). However, when motor activity was quantified $4 \mathrm{~h}$ after intraperitoneal 0.3 $\mathrm{mg} / \mathrm{kg}$ AMPH (Table 1, delayed-pairing group), the psychostimulant effect of the drug was no longer apparent and motor scores were even lower than those observed for saline-treated rats. This suggests the amount of AMPH remaining in the brain $4 \mathrm{~h}$ after injection was no longer sufficient to produce a psychomotor behavioral response (Honecker and Coper, 1975; Kuczenski and Segal, 1990, 1999).

The increased motor activity induced by a single $1.0 \mathrm{mg} / \mathrm{kg}$ intraperitoneal injection of AMPH (measured from 0 to $45 \mathrm{~min}$ after injection) was enhanced, or sensitized, subsequent to two additional intraperitoneal treatments (Table 1, Fig. 1). In contrast, although $0.3 \mathrm{mg} / \mathrm{kg}$ AMPH was sufficient to induce an acute motor effect, the magnitude of the response was not increased by two additional treatments ( $\mathrm{Ta}-$ ble 1, Fig. 1B). Motor scores obtained after repeated injections of saline showed a decrease on day 5 compared with that of day 1 (Table 1, Fig. $1 B$ ), consistent with habituation to the protocol (King et al., 2005).

Group B: context dependency of motor behavior

In a separate group of rats, we determined that the motor sensitization induced by $1.0 \mathrm{mg} / \mathrm{kg}$ AMPH was a conditioned response (i.e., it was context specific). Using the same treatment paradigm used for group A, rats that received the third repeated injection of $1.0 \mathrm{mg} / \mathrm{kg}$ AMPH on day 5 in an environment previously paired with AMPH developed motor sensitization from day 1 to day 5 ( $3628 \pm 201$ vs $4333 \pm 265$ beam breaks, respectively) (Fig. 1C). In contrast, no motor enhancement was observed if rats received AMPH on day 5 in an environment previously paired with saline (Fig. 1C). All other motor measurements also showed context dependency (data not shown). These results indicate that the environmental context linked to drug administration served as a critical cue for development of motor sensitization with this treatment protocol, and thus validating that the phenomenon was indeed a "conditioned" motor sensitization (i.e., CMS).

\section{AMPH-induced CPP}

To ascertain whether the environmental context was also mnemonically linked to the conditioned rewarding value of the drug, group A rats were tested for CPP on day 8 (Fig. $1 A$ ). Rats conditioned with saline or with the delayed-pairing AMPH paradigm did not show a preference for either side of the activity box on the CPP test day. When pairing was conducted without a delay between the injection and exposure to the chamber, both 0.3 and $1.0 \mathrm{mg} / \mathrm{kg}$ AMPH-treated rats expressed CPP on day 8 (132 \pm 45 vs $90 \pm 19$ s, respectively) (Fig. $1 B$ ). Therefore, consistent with our parallel study (Rademacher et al., 2006), the low dose of AMPH (i.e., $0.3 \mathrm{mg} / \mathrm{kg}$ ) was sufficient to induce CPP but was subthreshold to the dose needed to induce CMS (i.e., $1.0 \mathrm{mg} / \mathrm{kg}$ ). The difference in the AMPH threshold requirement suggested these two conditioned drug-induced behaviors might engage dif- 
A

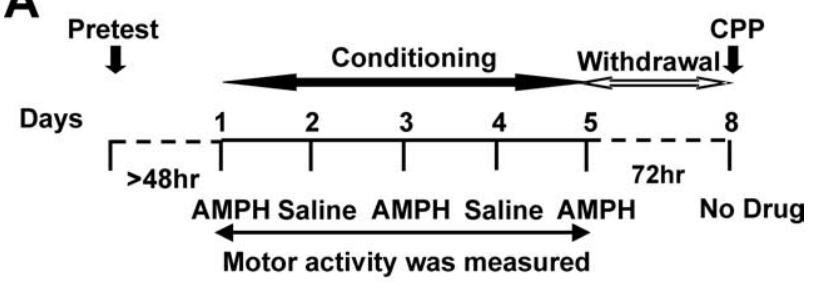

B Group A

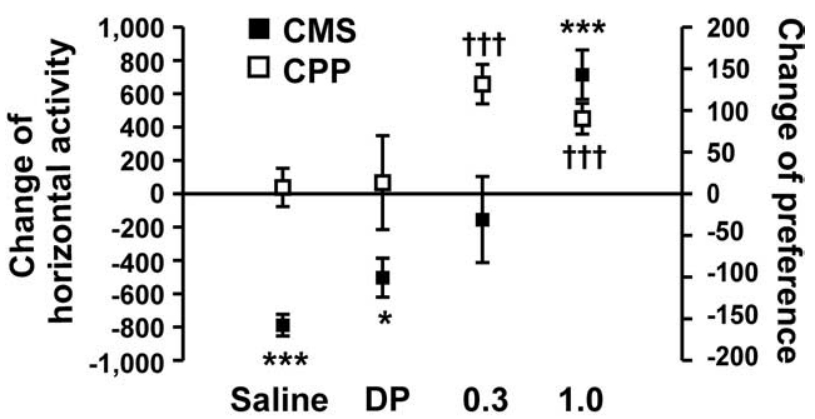

\section{Group B}

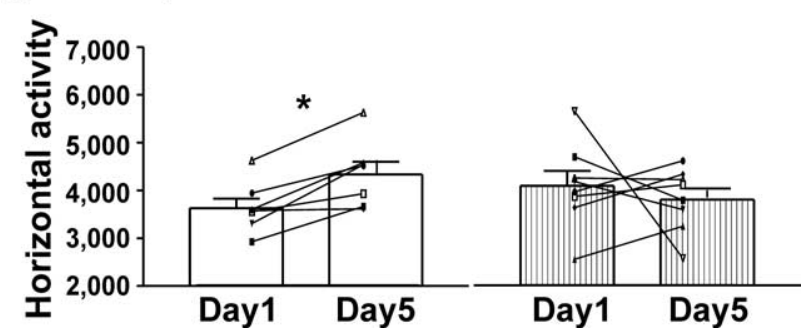

Figure 1. Different threshold doses were needed for AMPH-induced place preference and context-dependent motor sensitization. $\boldsymbol{A}$, Timeline of drug treatment and behavioral paradigm. $\boldsymbol{B}, \boldsymbol{C}$, CMS presented was measured on days 1 and 5 . CPP was assessed in the same rats on day 8. $\boldsymbol{B}$, Comparisons of CMS (filled square) and (PP (open square) for the four treatments (group A rats) studied. This graph illustrates that $0.3 \mathrm{mg} / \mathrm{kg} \mathrm{AMPH}$ was a discriminating dose, inducing CPP without motor sensitization, and $1.0 \mathrm{mg} / \mathrm{kg} \mathrm{AMPH}$ induced both behaviors. An example of CMS as the difference between horizontal scores obtained on day 5 from that on day 1 is shown on the left $y$-axis. Horizontal activity (photobeam breaks) was used as the example for CMS, because this behavior mirrored some other locomotor measures (see Table 1). An index of (PP presented as the "change of preference" (in seconds), obtained by determining the difference in time spent in the drug-paired and saline-paired sides on the CPP test day minus the difference in time spent in the drug-paired and saline-paired sides on the pretest day, is shown on the right $y$-axis. For rats receiving only saline, the side used on days 1,3 , and 5 is considered the "drug-paired" side. Data were averaged in 5 min bins to standardize between the $15 \mathrm{~min}$ pretest and $30 \mathrm{~min}$ (PP test periods. The saline and delayed-pairing (DP) groups did not express CPP, and during conditioning, these rats demonstrated a decrease in horizontal activity. For all experiments, data are shown as mean number \pm SEM for each group. Data from two-tailed one-sample $t$ tests (theoretic mean was set at zero, $\alpha$ value was Bonferroni adjusted to 0.0125 ) are as follows: for CMS: ${ }^{*} p<0.0125$, ${ }^{* * *} p<0.00025$; saline: $t_{(23)}=$ $12.07, p<0.0001 ; \mathrm{DP}: t_{(7)}=4.313, p=0.0035 ; 0.3 \mathrm{mg} / \mathrm{kg} \mathrm{AMPH:} t_{(15)}=0.5984, p=$ $0.5585 ; 1.0 \mathrm{mg} / \mathrm{kg} \mathrm{AMPH:} t_{(23)}=4.822, p<0.0001$; for CPP: ${ }^{\dagger+\dagger} p<0.00025$; saline: $t_{(23)}=0.3388, p=0.7378 ; \mathrm{DP}: t_{(7)}=0.2411, p=0.8164 ; 0.3 \mathrm{mg} / \mathrm{kg} \mathrm{AMPH:} t_{(15)}=$ $5.589, p<0.0001 ; 1.0 \mathrm{mg} / \mathrm{kg} \mathrm{AMPH:} t_{(23)}=4.863, p<0.0001$. C, Demonstration that motor sensitization was context dependent (group B rats). Horizontal activity induced by $1.0 \mathrm{mg} / \mathrm{kg}$ AMPH on days 1 and 5 is illustrated. Open bars, AMPH-induced activity on day 5 when the rats were placed in the side paired with AMPH on days 1 and 3; stippled bars, AMPH-induced activity on day 5 when the rats were placed in the side paired with saline on days 1 and 3. For all experiments, data are shown as mean number \pm SEM for each group (bar graph), with individual scores recorded from each rat (line graph overlay). ${ }^{*} p<0.005$, two-tailed paired $t$ test ( $\alpha$ value was Bonferroni adjusted to 0.025). Day 5 paired with the AMPH-conditioned side: $t_{(6)}=4.530, p=0.0040$; day 5 paired with the saline-conditioned side: $t_{(7)}=0.6447, p=0.5397$. ferent brain regions, and this possibility was explored using immunohistochemical assessments of TrkB receptor protein.

\section{Brain TrkB after AMPH-induced CMS and/or CPP}

Immunoreactivity for TrkB was quantified in the hippocampus, blA, NAc, and VP based on two criteria: these regions are known to be involved in reward (Gong et al., 1996; Gooney and Lynch, 2001; Chao and Nestler, 2004) and with qualitative assessment showed TrkB staining. Immunohistochemical quantification revealed that the CA3/DG subfields of the hippocampus increased in TrkB staining in rats showing CPP induced by the 0.3 and 1.0 $\mathrm{mg} / \mathrm{kg}$ AMPH compared with saline and delayed-pairing control groups (Fig. 2C). Linear regression analysis of both AMPH doses revealed that the magnitude of CPP score (described in legend to Fig. 1) induced by AMPH did not correlate to the density of TrkB immunolabeling in the DG $\left(F_{(10)}=0.2227 ; r^{2}=0.027 ; p=\right.$ $0.6496)$ or CA3 subfield $\left(F_{(10)}=3.405 ; r^{2}=0.2984 ; p=0.1022\right)$. With $1.0 \mathrm{mg} / \mathrm{kg}$ AMPH, which induced both CPP and CMS, TrkB was elevated in the shell of NAc in addition to the CA3/DG (Fig. $2 C)$. Again, there was no correlation between the magnitude of the CMS (described in the legend to Fig. 1) versus the TrkB immunolabeling in the shell of NAc $\left(F_{(6)}=0.1235 ; r^{2}=0.02995 ; p\right.$ $=0.7430$ ). In the CA1 hippocampal subfield, $1.0 \mathrm{mg} / \mathrm{kg}$ AMPH increased TrkB staining compared with saline and delayedpairing treatments, but in the VP, differences only occurred between $1.0 \mathrm{mg} / \mathrm{kg}$ AMPH and saline (Table 2). These results suggest that the CA1 may be involved in certain context-dependent behaviors; however, the VP may predominantly influence "drugonly" effects instead of the associative learning. AMPH did not alter TrkB immunoreactivity in either the blA or core of NAc (Table 2). There was no difference between the saline and delayed-pairing groups $(p>0.05)$ in any regions quantified, which distinguished the drug effect from the drug-induced learning. These findings indicate that the two conditioned responses, induced by different doses of AMPH, reflect adaptations in brain regions specific for reward and learning and that TrkB might be involved.

Similar to what was observed with TrkB IH, TrkB mRNA levels were increased in the DG of rats showing AMPH (1.0 mg/ kg)-induced CPP (Fig. 3). The converging evidences from both $\mathrm{IH}$ and in situ hybridization demonstrate the involvement of TrkB in the hippocampus in AMPH-induced conditioned learning and implicate gene transcription and protein synthesis in the process.

\section{Intra-DG/CA3 infusion of K-252a disrupted the AMPH-induced CPP and CMS}

To ascertain whether the hippocampal TrkB receptors are necessary for conditioned behaviors, rats bearing bilateral indwelling cannulas aimed at the DG/CA3 subfields (Fig. 4) were conditioned as in the previous experiments. The tyrosine kinase inhibitor K-252a was injected bilaterally into the DG/CA3 region (25 $\mathrm{ng} / 0.5 \mu \mathrm{l}$ of $25 \% \mathrm{DMSO} /$ saline per side) immediately before 1.0 $\mathrm{mg} / \mathrm{kg}$ intraperitoneal AMPH or saline, administered once every other day (Fig. 5A). Rats receiving this intracerebral treatment failed to develop either CMS (Table 3, Fig. 5B) or CPP (Fig. 5C). To ascertain the anatomical specificity of this effect, a separate group of animals received same intracerebral K-252a and systemic AMPH injections, with the exception that K-252a was infused into the overlying associative cortex (immediately dorsal toDG/CA3). These rats developed both conditioned behaviors (CMS, $3023 \pm 545$ beam breaks on day 1 vs $4427 \pm 341$ beam breaks on day 5; CPP, $1299 \pm 129 \mathrm{~s}$ in the drug-paired side vs 
$307 \pm 69 \mathrm{~s}$ in the saline-paired side) (Fig. $5 B, C)$. Intra-DG/CA3 injections of the DMSO vehicle solution did not interfere with the ability of the rats to acquire CMS (Table 3, Fig. 5B) and CPP (940 \pm $58 \mathrm{~s}$ spent in the AMPH-paired side vs $539 \pm 40 \mathrm{~s}$ spent in the saline-paired side) (Fig. 5C) after three alternative day pairings of $1.0 \mathrm{mg} / \mathrm{kg}$ AMPH. The intraDG/CA3 injections of K-252a did not cause place aversion (or preference; 680 $\pm 98 \mathrm{~s}$ spent in the K252a-paired side vs $704 \pm 118 \mathrm{~s}$ spent in the sham-injected side) (Fig. $5 C$ ) or alter the acute motor responses to $1.0 \mathrm{mg} / \mathrm{kg}$ AMPH (Table 3, Fig. $5 B$ ). In summary, these results suggested that the hippocampal Trk receptors were necessary for the induction of both AMPH-induced CMS and CPP.

To determine whether the effects of $\mathrm{K}-252 \mathrm{a}$ on the induction of conditioning reflected a specific receptor antagonizing rather than a permanent damage to the hippocampus, rats that had previously received intra-DG/CA3 infusions in the initial training session were "reconditioned" (from days 15 to 19) and retested for CPP on day 22 in a drug-free state after a 1 week rest in their home cage without any treatment (Fig. 6A). AMPH (1.0 mg/kg) was paired on days 15,17 , and 19 without intracerebral injection. Rats that received intra-DG/CA3 vehicle expressed CMS and CPP on day 8 (Fig. 5C) and day $22(920 \pm$ $86 \mathrm{~s}$ in the AMPH-paired side vs $487 \pm 56$ $s$ in the saline-paired side) (Fig. 6B). Moreover, after these additional AMPH pairings, rats previously treated (on days 1, 3 , and 5) with intra-DG/CA3 K-252a and intraperitoneal AMPH (and failed to express AMPH-induced CPP on day 8) retained their capacity to learn, and expression was observed on day 22 CPP (944 \pm $65 \mathrm{~s}$ in the AMPH-paired side vs $486 \pm 51$ $s$ in the saline-paired side) (Fig. 6B). This suggests that the effect of the antagonist was a result of temporary blockade of Trk receptors but not to permanent damage or alteration of receptor function. Rats previously treated with intra-DG/CA3 K-252a plus intraperitoneal saline and conditioned with $1.0 \mathrm{mg} / \mathrm{kg} \mathrm{AMPH}$ in the absence of K-252a on days 15-19 subsequently demonstrated CMS (Table 3 ) and expressed CPP on day $22(890 \pm 84 \mathrm{~s}$ in the AMPH-paired side vs $526 \pm 77 \mathrm{~s}$ in the saline-paired side) (Fig. 6B). Therefore, it seems that blocking the ability of endogenous neurotrophins to activate the hippocampal TrkB receptors during initial conditioning does not influence the capacity to acquire future $\mathrm{AMPH}$-induced associations.

We further discriminated the effect of K-252a on AMPHinduced CPP expression (after the memory developed) from the

\section{A Bregma: +1.6}
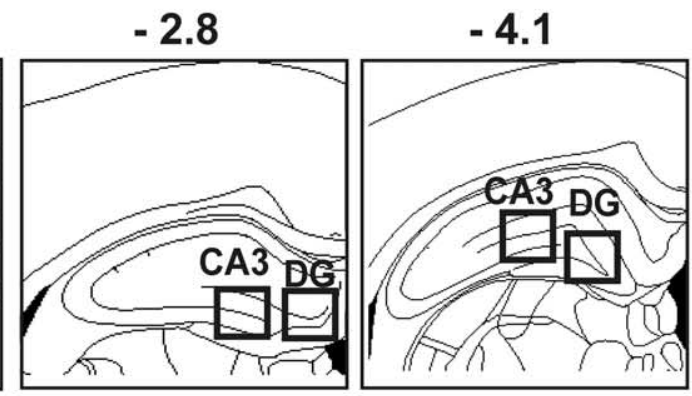

\section{B
DG}

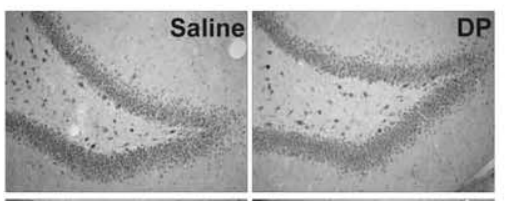

CA3
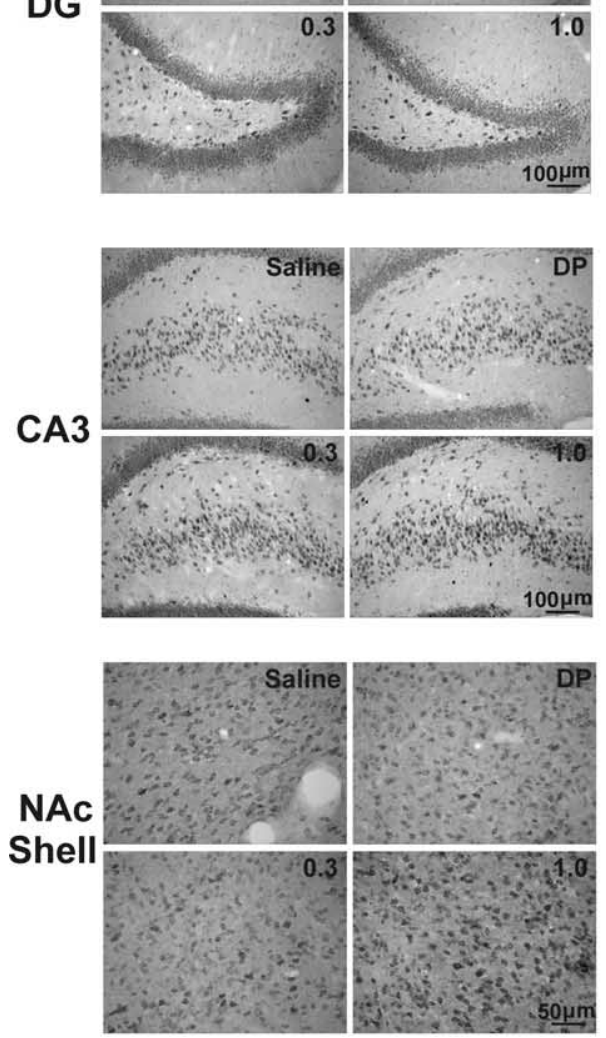
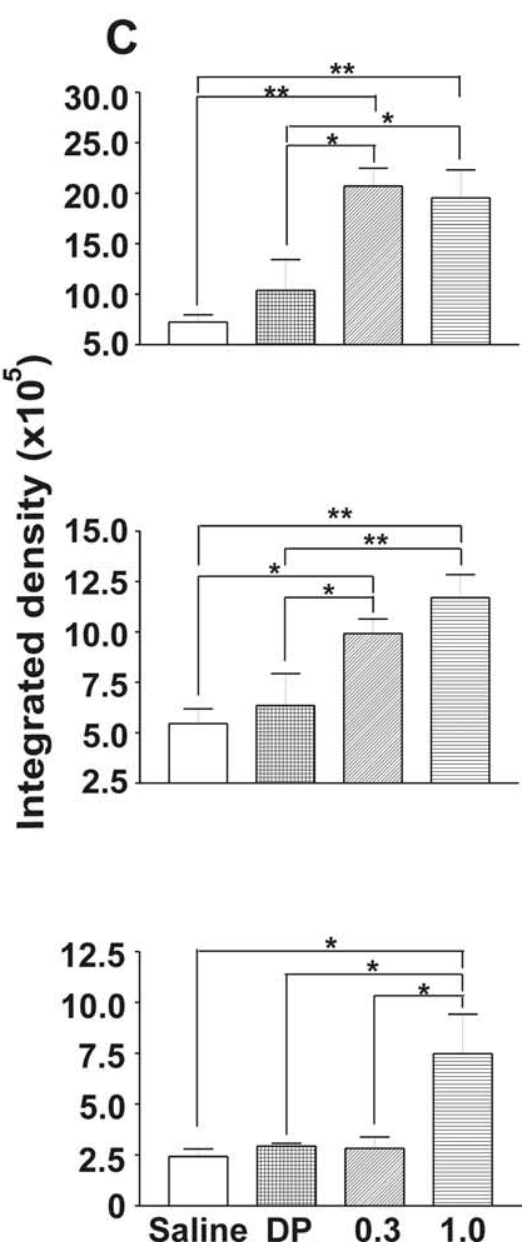

Figure 2. Immunohistochemical staining for TrkB in hippocampal subfields (CA3 and DG) and the shell region of the NAC (NAC shell) was upregulated after AMPH-induced (PP and CMS. $\boldsymbol{A}$, Areas used for IH quantification are indicated with square boxes. Stereotaxic maps were adapted from Paxinos and Watson (1998). B, Representative photomicrographs of TrkB staining in DG and CA3 hippocampal subfields and in the NAc shell taken from rats treated with saline, delayed pairing (DP), and 0.3 and $1.0 \mathrm{mg} / \mathrm{kg}$ AMPH. Scale bars are as indicated. C, TrkB-like immunoreactivity in CA3 and DG subfields was increased in the rats showing AMPH-induced CPP. In the NAc shell, TrkB level was elevated only in the rats treated with the higher dose $(1.0 \mathrm{mg} / \mathrm{kg})$ of AMPH. The integrated density quantification of TrkB staining for the corresponding regions is shown in $B$. Three consecutive slices from the locations illustrated in $\boldsymbol{A}$ were averaged (see Materials and Methods). For the CA3 and DG, paired $t$ test evaluations were not different for sections taken from bregma, -2.8 and $-4.1 \mathrm{~mm}$; thus, these were averaged for each rat for additional analysis (as shown in $\left(\right.$ ). Data are shown as mean \pm SEM for each group. Data from one-way ANOVA are as follows: DG: $F_{(3,17)}=9.871, p=$ $0.0006 ;$ CA3: $F_{(3,17)}=7.588, p=0.0026$; NAc shell: $F_{(3,17)}=4.845, p=0.012$. Data from the post hoc Newman-Keuls test are as follows: ${ }^{*} p<0.05, q=3.432-4.862 ;{ }^{* *} p<0.01, q=4.951-6.540$.

acquisition phase. To do so, we used a group of rats $(n=6)$ that failed to express CPP on day 8 after conditioning with intra-DG K-252a plus intraperitoneal AMPH (on days 1-5) but that did express CPP on day 22 after reconditioning with AMPH alone (from days 15 to 19) (Figs. 5C, 6B, diagonal filled bars). These rats 

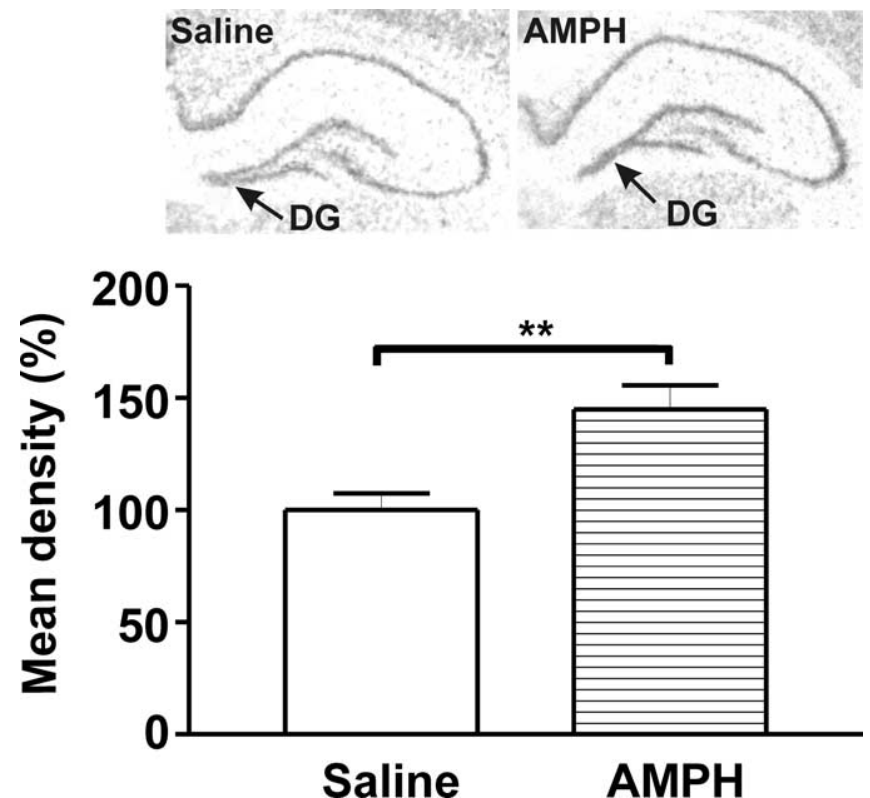

Figure 3. In situ hybridization staining for TrkB mRNA in the DG of the hippocampus. Representative photomicrographs are shown. The corresponding bar graph illustrates that TrkB mRNA was upregulated after AMPH $(1.0 \mathrm{mg} / \mathrm{kg})$-induced CPP. Data are shown as mean density \pm SEM for each group. Student's $t$ test and values are expressed as percentage of controls. ${ }^{* *} p<0.01 ; t_{(10)}=3.483 ; p=0.0059$.

received the same intra-DG/CA3 dose of the Trk antagonist $\mathrm{K}-252 \mathrm{a}$ on day 23 immediately before being subjected to the CPP test (no systemic injections were administered). These rats expressed CPP, even when K-252a was present in the brain, spending significantly more time on the drug-paired side (982 $\pm 78 \mathrm{~s})$ compared with the saline-paired side $(427 \pm 46 s)(p<0.01$, paired $t$ test). Although additional studies are needed with, for example, proper intra-DG vehicle, the findings suggest that Trk receptors in the DG/CA3 are involved in development but not expression of AMPH-induced CPP.

\section{Discussion}

Dose-effect evaluations of AMPH on behavior and

TrkB expression

CMS and CPP develop when a psychostimulant is repeatedly administered in the context of a specific environment (Segal and Mandell, 1974; Wise et al., 1976; Segal et al., 1981; Vezina and Stewart, 1984; Robinson and Becker, 1986; Gold et al., 1988). In laboratory rats, these behavioral outcomes share many common neuronal features and thus it has been argued that these two behaviors represent adaptations in common brain substrates (for review, see Robinson and Berridge, 2000; Vanderschuren and Kalivas, 2000). The current study revealed that TrkB is differentially expressed in rats showing CPP only, versus those that also exhibit CMS, which adds to the growing body of evidence that distinguishes the two (Swerdlow and Koob, 1984; Hemby et al., 1992; Olmstead and Franklin, 1994; Rademacher et al., 2006). First, we observed pharmacological differences; three repeated injections of $0.3 \mathrm{mg} / \mathrm{kg}$ AMPH were sufficient to induce CPP, without inducing a sensitized motor response as assessed by several indices of motoric function. We determined that a higher dose, $1.0 \mathrm{mg} / \mathrm{kg}$, retained the capacity to induce CPP and also was sufficient to induce CMS. Second, we observed differences in neuroanatomical substrates associated with these behaviors (i.e., the Trk receptor for neurotrophic factors was uniquely upregu-
A
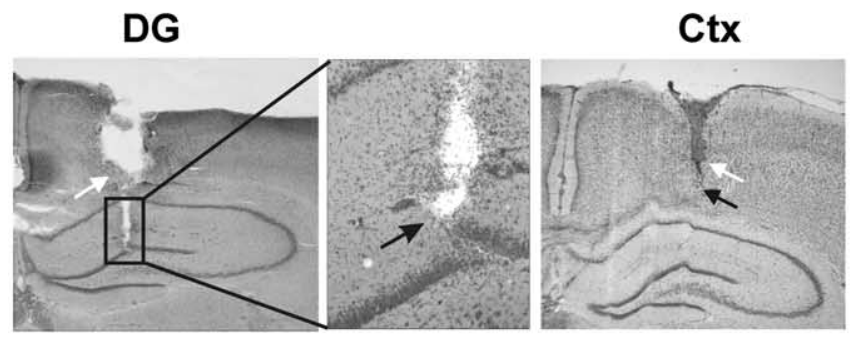

B

$-2.12$

Intra-DG K252a Controls

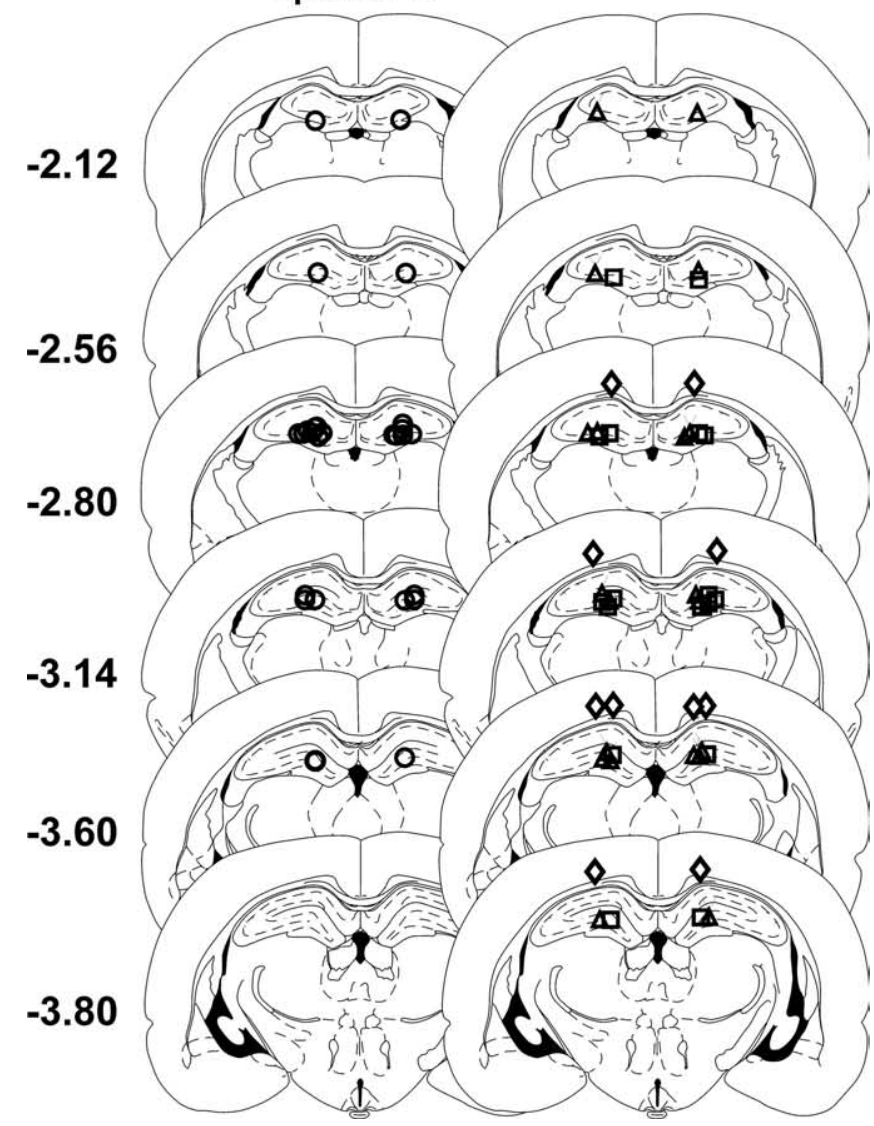

Figure 4. Intracerebral injection sites. $\boldsymbol{A}$, Photomicrographs of Nissl-stained coronal brain sections showing cannulas (white arrows) and injector tips (black arrows). The left and middle panels show the DG in low and high magnification, respectively. The right panel shows the overlying cortex (Ctx; low magnification). B , Illustration of the injector tip location for all intracerebral sites tested. Sterotaxic maps were adapted from the atlas of Paxinos and Watson (1998). The numbers refer to the coronal locale of the section, in millimeters relative to bregma. In the left maps, the injector tip location from rats receiving intra-DG/CA3 (DG) K-252a followed by intraperitoneal $1.0 \mathrm{mg} / \mathrm{kg}$ AMPH are illustrated $(O ; n=14)$. In the right maps, the following controls are illustrated: $\triangle$, intra-DG vehicle with intraperitoneal $1.0 \mathrm{mg} / \mathrm{kg} \mathrm{AMPH}(n=10) ; \square$, intra-DG K-252a with intraperitoneal saline $(n=8) ; \diamond$, intra-cortex K-252a with intraperitoneal $1.0 \mathrm{mg} / \mathrm{kg}$ AMPH $(n=5)$. The sites injected in each treatment group overlapped, revealing that similar regions were evaluated.

lated in the DG/CA3 hippocampal subfields during the learning processes engendered by the low dose of AMPH, but this drug effect did not occur in the absence of learning resulting from temporally separating the conditioned and unconditioned stimuli). Moreover, changes did not occur in the NAc until the high, motor-enhancing dose of AMPH was used. The results show that 
A

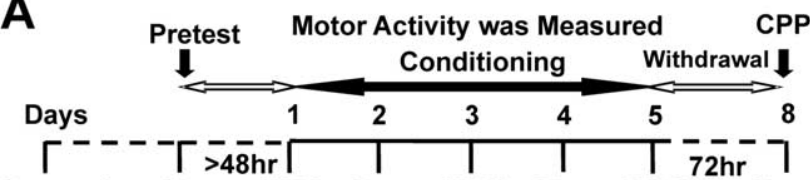

Surgeryi.c.: Sham K252a Sham K252a Sham K252a Sham

i.p.: AMPH Saline AMPH Saline AMPH No Drug

B

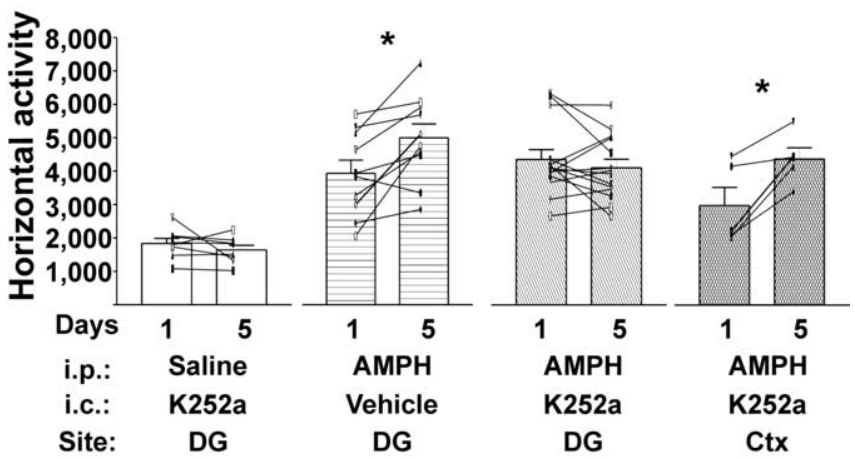

\section{Day 8: CPP test}
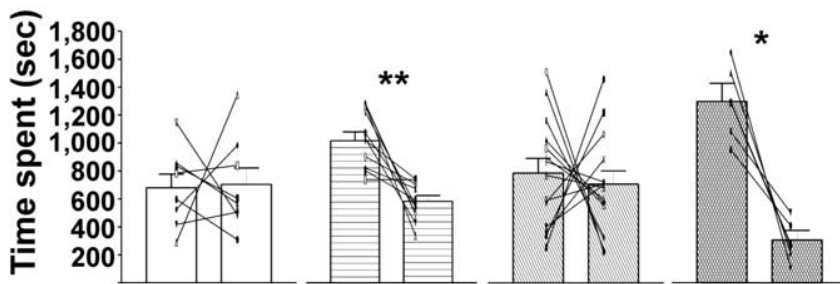

Saline Saline AMPH Saline AMPH Saline AMPH Saline K252a Sham Vehicle Sham K252a Sham K252a Sham $\begin{array}{llll}\text { Site: } & \text { DG } & \text { DG } & \text { DG }\end{array}$

Figure 5. Development of AMPH-induced CMS and CPP require hippocampal Trk receptors. A, Timeline of intracerebral and systemic drug treatments and the behavioral paradigms. On AMPH-conditioning days 1,3 , and 5, the tyrosine kinase inhibitor K-252a ( $25 \mathrm{ng} / 0.5 \mu \mathrm{l}$ of $25 \%$ DMSO in saline per side) or its vehicle was infused intracerebrally into the DG/CA3 (DG) or cortex immediately before each systemic injection ( $1.0 \mathrm{mg} / \mathrm{kg} \mathrm{AMPH}$ or saline), and rats were placed into the activity chambers. $\boldsymbol{B}, \boldsymbol{C}$, Intracerebral injections listed are those given on days 1,3 , and 5; vehicle was $25 \%$ DMSO in saline. Data are presented as mean \pm SEM. ${ }^{*} p<0.0125 ;{ }^{* *} p<$ 0.0025; two-tailed paired $t$ test ( $\alpha$ value was Bonferroni adjusted to 0.0125 ). $\boldsymbol{B}$, Horizontal activity. AMPH induced CMS in rats pretreated with intra-DG vehicle or intra-cortex K-252a. Rats pretreated with intra-DG K-252a failed to develop AMPH-induced CMS. DG K-252a with intraperitoneal saline, $t_{(7)}=1.089, p=0.3124$; DG vehicle with intraperitoneal AMPH, $t_{(9)}=$ $3.374, p=0.0082$; DG K-252a in the DG with intraperitoneal AMPH, $t_{(13)}=1.118, p=0.2838$; cortex K-252a in the cortex with intraperitoneal AMPH, $t_{(4)}=3.836, p=0.0105$. C, CPP. Rats conditioned with intra-DG K-252a before AMPH intraperitoneally on days 1,3 , and 5 failed to express AMPH-induced CPP on the test day (day 8), whereas (PP remained intact in rats conditioned with intra-DG vehicle or intra-cortex K-252a. DG K-252a with intraperitoneal saline, $t_{(7)}=0.1284, p=0.9014 ; \mathrm{DG}$ vehicle with intraperitoneal $\mathrm{AMPH}, t_{(9)}=4.425, p=0.0017 ; \mathrm{DG}$ K-252a with intraperitoneal AMPH, $t_{(13)}=0.4129, p=0.6864$; cortex K-252a with intraperitoneal AMPH, $t_{(4)}=5.096, p=0.0070$. i.c., Intracerebral; i.p., intraperitoneal; $\mathrm{Ctx}$, cortex.

low doses of AMPH can result in TrkB increases in the hippocampus along with CPP expression, an index of conditioned reward value (Bardo and Bevins, 2000), independent of overt motor effects. These results thus indicate that drug reward induced by such low AMPH doses (Gaiardi et al., 2001) appears to be distinct from TrkB changes in the accumbens, likely resulting from

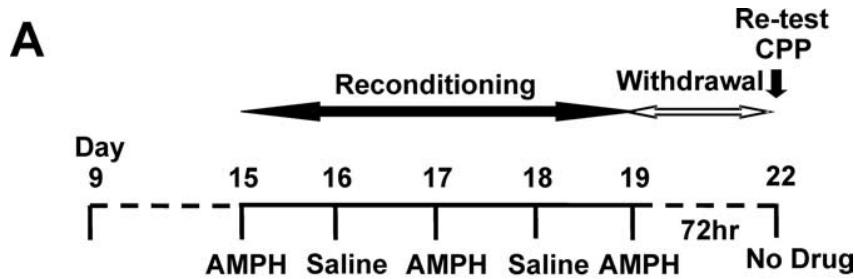

B Day 22

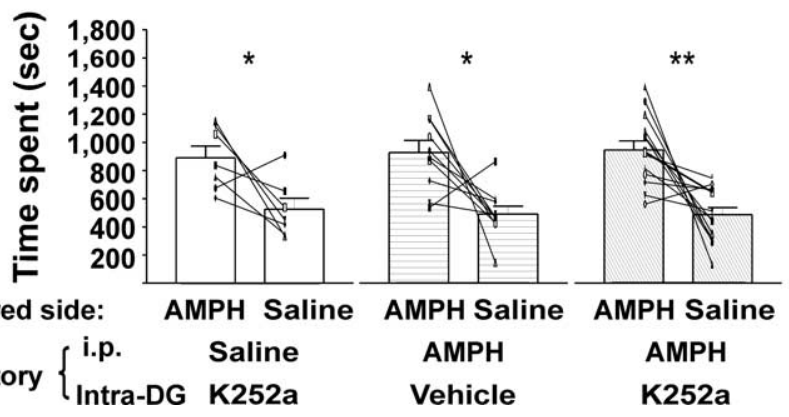

Figure 6. The capacity to acquire learned associations recovered in rats that did not show AMPH-induced conditioning with intrahippocampal injections of the Trk antagonists K-252a. The data show that effects of K-252a were attributable to antagonizing hippocampal TrkB receptors during AMPH conditioning but not any permanent damage to the brain region. $\boldsymbol{A}$, Timeline of treatment and behavioral paradigms. B, K-252a $(25 \mathrm{ng} / 0.5 \mu \mathrm{l})$ did not affect the capacity of the animal to acquire AMPH-induced place learning after antagonist was no longer present in the brain. After "retraining," rats spent more time on the AMPH-paired side in all three groups regardless of the drug treatment history in the first training session (days 1-5). For all experiments, data are presented as mean \pm SEM. ${ }^{*} p<0.0167,{ }^{* *} p<0.003$ [two-tailed paired $t$ test ( $\alpha$ value was Bonferroni adjusted to 0.0167 )]. Rats with a history of intra-DG $\mathrm{K}$-252a with intraperitoneal saline, $t_{(6)}=3.731, p=0.0141$; intra-DG vehicle with intraperitoneal AMPH, $t_{(9)}=3.216, p=0.0105$; intra-DG K-252a with intraperitoneal AMPH, $t_{(13)}=$ $4.176, p=0.0011$.

changes in monoaminergic transmission that bypass accumbal TrkB signaling. Whereas drug-associated learning or conditioning may uniquely involve the hippocampus. The latter possibility was explored further in the final experiment, in which we demonstrated that AMPH-mediated induction of both forms of conditioning (i.e., CPP and CMS) required activation of Trk receptors in the DG/CA3, thus providing a plausible mechanism underlying the ability of AMPH to engender conditioned responding.

Role of the Trk system in drug-induced context-dependent behaviors

The current study demonstrated that Trk receptors in the hippocampus are critical for context-dependent associative learning. Neurotrophic factors and their cognate Trk receptors are essential to learning and memory (Tyler et al., 2002; Purcell and Carew, 2003). The disruption of AMPH-induced contextdependent behaviors with intra-DG infusions of the Trk antagonist K-252a during acquisition of drug/context associations indicates the hippocampal Trk system is critical for this type of learning. This effect was reversible, because CPP and CMS were established with AMPH reconditioning when the antagonist was no longer present in the system. Together, these studies provide strong evidence that the acquisition of conditioned learning and the development of a conditioned motoric response to AMPH require the neurotrophic receptor activation in the hippocampus. 
Because K-252a is a nonselective Trk receptor antagonist, acting on TrkA, TrkB, and TrkC receptors (Tapley et al., 1992), the current results from intracerebral injections of $\mathrm{K}-252 \mathrm{a}$ are not conclusive for an involvement of the TrkB subtype. They are consistent, however, with our IH demonstration of TrkB upregulation after development of AMPH-induced conditioning. Various negative controls (primary omit, blocking peptide, and normal rabbit IgG), as well as the similar staining pattern obtained as the antibodies raised on site (Yan et al., 1997), demonstrated the IH results did not likely reflect nonselective staining of TrkA and TrkC receptors. Our findings also concur with demonstrations of BDNF and TrkB involvement in acquisition of other fundamental forms of associative learning that reflect emotionally laden stimuli paired with a particular context (e.g., fear conditioning) (Hall et al., 2000; Rattiner et al., 2004; Ou and Gean, 2006). Moreover, Rattiner et al. (2004) demonstrated that the ability of K-252a to block associative fear learning mirrored that seen with a lentiviral vector expressing a dominant-negative TrkB isoform that is highly specific for TrkB.

\section{Hippocampal circuits and drug-induced associative learning} The present results agree with the well accepted role for the hippocampus in the acquisition of new information, shown both in rats (Kim and Fanselow, 1992) and humans (Scoville and Milner, 1957). The results also enhance our understanding of the role of TrkB receptors in neural system dynamics that contribute to drug-induced associative learning. Abused drugs, such as AMPH, are thought to serve as an UCS and are rewarding by virtue of their ability to increase dopamine concentrations in termination sites of ventral tegmental area projections, such as the NAc (Gold et al., 1989). Anatomical assessments describe circuits that provide a means for this "reward message" to be relayed to the blA and back to the hippocampus (Finch et al., 1986; Jas et al., 2000). Sensory information regarding environmental context (i.e., the CS) that is temporally associated with an UCS also is processed in the hippocampus (Buchel et al., 1999). This reward-context link is strengthened with repeated CS-UCS pairing and, based on the present results, likely involves increased expression of TrkB receptors in the DG/CA3 hippocampal subfields. Activation of TrkB receptors increases glutamatergic transmission in the hippocampus by increasing the presynaptic glutamate release (Lessmann, 1998) and postsynaptically by phosphorylating NMDA receptors (Suen et al., 1997). This promotes NMDA facilitation of dendritic spine $\mathrm{Ca}^{2+}$ influx to enhance intracellular signaling mechanisms that underlie LTP (Tyler et al., 2002), a putative cellular mechanism of learning and memory. Changes in TrkBmediated neuronal activity alter the strength of hippocampal outputs that ultimately influence drug/context-dependent behaviors; candidate structures include NAc, blA, and VP. Although TrkB did not appear to be critically regulated in these regions (current study), each region does show increased c-Fos and synaptophysin with the AMPH-induced CPP/CMS paradigm used here (Rademacher et al., 2006). Thus, adaptations in TrkB receptor function in the hippocampus is critical for making associations between drug UCS and contextual CS, and these changes engage various other mechanisms of neuroplasticity in other regions of the limbic circuit to influence the expression of conditioned behaviors.

Recent electrophysiological investigations of the NAc provide insight into how alterations in hippocampus drive can bring about changes in the function of hippocampal-associated structures. The hippocampus provides inputs to the NAc that contain glutamate (O'Donnell and Grace, 1995) that regulates dopami- nergic transmission in this region (Nicola et al., 2000) and influences the motor stimulant effects of AMPH (Parkinson et al., 1999). Hippocampal inputs to the NAc also determine the impact of glutamatergic influences from other sources, including the prefrontal cortex (O'Donnell and Grace, 1995; O’Donnell et al., 1999). Purportedly, the hippocampus imposes a modest depolarization on a subset of NAc medium spiny neurons, moving them from a hyperpolarized (termed "down") state to a subthreshold depolarized (termed "up") state (O’Donnell et al., 1999), and, in so doing, makes these accumbal neurons more likely to generate action potentials in response to synchronous activation of glutamatergic afferent inputs from other regions including the prefrontal cortex (O'Donnell and Grace, 1995; O'Donnell et al., 1999; Parkinson et al., 1999; Vorel et al., 2001; Everitt and Robbins, 2005). Upregulation of TrkB receptors would enhance NMDA-mediated spiking of hippocampal outputs (Suen et al., 1997), switching more accumbal neurons to their up state, and thus promote behaviors regulated by the NAc. This line of thinking implies that those NAc neurons contacted by hippocampal neurons that upregulate TrkB with low-dose AMPH in the current study are more critically involved in reward mechanisms, whereas NAc neurons recruited by hippocampal inputs that upregulate TrkB only after high-dose AMPH are the NAc neurons that are more involved in motor function. The notion that both of these output consequences are initiated via hippocampal TrkB receptors is supported by our discovery that blocking these receptors is sufficient to antagonize both CMS and CPP, and by implication, this is accomplished by leaving a significant portion of NAc cells in down state.

VP (Golmayo et al., 2003) and blA (Farb and LeDoux, 1999) neuronal activity also are regulated by hippocampal and cortical activation, and VP neurons are known to exhibit up and down states (Lavin and Grace, 1996) similar to that reported for the NAc. It would be of interest to ascertain hippocampal influences on these regions mirror that observed for the NAc and whether these are altered during AMPH-induced CPP/CMS.

In summary, our results indicate that $\operatorname{TrkB}$ receptors in the hippocampus may be one of the common and critical mediators of the neuronal changes necessary for the induction of both forms of conditioning. As the hippocampus and its connected circuitry are profoundly affected by drugs of abuse, it may indeed be that the synaptic mechanisms regulated by neurotrophic factors and their cognate receptors underlie long-lasting changes that contribute to the intensity and persistence of the drug memory in the drug-withdrawn addict.

\section{References}

Anagnostaras SG, Robinson TE (1996) Sensitization to the psychomotor stimulant effects of amphetamine: modulation by associative learning. Behav Neurosci 110:1397-1414

Bardo MT, Bevins RA (2000) Conditioned place preference: what does it add to our preclinical understanding of drug reward? Psychopharmacology (Berl) 153:31-43.

Browman KE, Badiani A, Robinson TE (1998) Modulatory effect of environmental stimuli on the susceptibility to amphetamine sensitization: a dose-effect study in rats. J Pharmacol Exp Ther 287:1007-1014.

Buchel C, Dolan RJ, Armony JL, Friston KJ (1999) Amygdala-hippocampal involvement in human aversive trace conditioning revealed through event-related functional magnetic resonance imaging. J Neurosci 19:10869-10876.

Chao J, Nestler EJ (2004) Molecular neurobiology of drug addiction. Annu Rev Med 55:113-132.

Dragunow M, Hughes P, Mason-Parker SE, Lawlor P, Abraham WC (1997) TrkB expression in dentate granule cells is associated with a late phase of long-term potentiation. Brain Res Mol Brain Res 46:274-280. 
Everitt BJ, Robbins TW (2005) Neural systems of reinforcement for drug addiction: from actions to habits to compulsion. Nat Neurosci 8:1481-1489.

Farb CR, LeDoux JE (1999) Afferents from rat temporal cortex synapse on lateral amygdala neurons that express NMDA and AMPA receptors 13. Synapse 33:218-229.

Figurov A, Pozzo-Miller LD, Olafsson P, Wang T, Lu B (1996) Regulation of synaptic responses to high-frequency stimulation and LTP by neurotrophins in the hippocampus. Nature 381:706-709.

Finch DM, Wong EE, Derian EL, Chen XH, Nowlin-Finch NL, Brothers LA (1986) Neurophysiology of limbic system pathways in the rat: projections from the amygdala to the entorhinal cortex. Brain Res 370:273-284.

Gaiardi M, Gubellini C, Dall'Olio R, Gandolfi O, Bartoletti M (2001) Effects of $\mathrm{N}$-methyl-D-aspartate agonists and antagonists in rats discriminating amphetamine. Behav Pharmacol 12:317-324.

Geinisman Y (2000) Structural synaptic modifications associated with hippocampal LTP and behavioral learning. Cereb Cortex 10:952-962.

Geinisman Y, Disterhoft JF, Gundersen HJ, McEchron MD, Persina IS, Power JM, Van der Zee EA, West MJ (2000) Remodeling of hippocampal synapses after hippocampus-dependent associative learning. J Comp Neurol 417:49-59.

Gold LH, Swerdlow NR, Koob GF (1988) The role of mesolimbic dopamine in conditioned locomotion produced by amphetamine. Behav Neurosci 102:544-552.

Gold LH, Geyer MA, Koob GF (1989) Neurochemical mechanisms involved in behavioral effects of amphetamines and related designer drugs. NIDA Res Monogr 94:101-126.

Golmayo L, Nunez A, Zaborszky L (2003) Electrophysiological evidence for the existence of a posterior cortical-prefrontal-basal forebrain circuitry in modulating sensory responses in visual and somatosensory rat cortical areas 2. Neuroscience 119:597-609.

Gong WH, Neill DB, Justice Jr JB (1996) Locomotor response to novelty does not predict cocaine place preference conditioning in rats. Pharmacol Biochem Behav 53:191-196.

Gooney M, Lynch MA (2001) Long-term potentiation in the dentate gyrus of the rat hippocampus is accompanied by brain-derived neurotrophic factor-induced activation of TrkB. J Neurochem 77:1198-1207.

Grimm JW, Lu L, Hayashi T, Hope BT, Su TP, Shaham Y (2003) Timedependent increases in brain-derived neurotrophic factor protein levels within the mesolimbic dopamine system after withdrawal from cocaine: implications for incubation of cocaine craving. J Neurosci 23:742-747.

Hall J, Thomas KL, Everitt BJ (2000) Rapid and selective induction of BDNF expression in the hippocampus during contextual learning. Nat Neurosci 3:533-535.

Hemby SE, Jones GH, Justice Jr JB, Neill DB (1992) Conditioned locomotor activity but not conditioned place preference following intra-accumbens infusions of cocaine. Psychopharmacology (Berl) 106:330-336.

Honecker H, Coper H (1975) Kinetics and metabolism of amphetamine in the brain of rats of different ages. Naunyn Schmiedebergs Arch Pharmacol 291:111-121.

Horger BA, Iyasere CA, Berhow MT, Messer CJ, Nestler EJ, Taylor JR (1999) Enhancement of locomotor activity and conditioned reward to cocaine by brain-derived neurotrophic factor. J Neurosci 19:4110-4122.

Jas J, Almaguer W, Frey JU, Bergado J (2000) Lesioning the fimbria-fornix impairs basolateral amygdala induced reinforcement of LTP in the dentate gyrus. Brain Res 861:186-189.

Kilts CD, Schweitzer JB, Quinn CK, Gross RE, Faber TL, Muhammad F, Ely TD, Hoffman JM, Drexler KP (2001) Neural activity related to drug craving in cocaine addiction. Arch Gen Psychiatry 58:334-341.

Kim JJ, Fanselow MS (1992) Modality-specific retrograde amnesia of fear. Science 256:675-677.

King JA, Garelick TS, Brevard ME, Chen W, Messenger TL, Duong TQ, Ferris CF (2005) Procedure for minimizing stress for fMRI studies in conscious rats. J Neurosci Methods 148:154-160.

Kuczenski R, Segal DS (1990) In vivo measures of monoamines during amphetamine-induced behaviors in rats. Prog Neuropsychopharmacol Biol Psychiatry [Suppl] 14:S37-S50.

Kuczenski R, Segal DS (1999) Sensitization of amphetamine-induced stereotyped behaviors during the acute response. J Pharmacol Exp Ther 288:699-709.

Lavin A, Grace AA (1996) Physiological properties of rat ventral pallidal neurons recorded intracellularly in vivo. J Neurophysiol 75:1432-1443.
Lessmann V (1998) Neurotrophin-dependent modulation of glutamatergic synaptic transmission in the mammalian CNS. Gen Pharmacol 31:667-674.

Lu L, Dempsey J, Liu SY, Bossert JM, Shaham Y (2004) A single infusion of brain-derived neurotrophic factor into the ventral tegmental area induces long-lasting potentiation of cocaine seeking after withdrawal. J Neurosci 24:1604-1611.

Lu W, Monteggia LM, Wolf ME (2002) Repeated administration of amphetamine or cocaine does not alter AMPA receptor subunit expression in the rat midbrain. Neuropsychopharmacology 26:1-13.

McAllister AK, Katz LC, Lo DC (1999) Neurotrophins and synaptic plasticity. Annu Rev Neurosci 22:295-318.

Meredith GE, Callen S, Scheuer DA (2002) Brain-derived neurotrophic factor expression is increased in the rat amygdala, piriform cortex and hypothalamus following repeated amphetamine administration. Brain Res 949:218-227.

Meyers RA, Zavala AR, Neisewander JL (2003) Dorsal, but not ventral, hippocampal lesions disrupt cocaine place conditioning. NeuroReport 14:2127-2131.

Milner B, Penfield W (1955) The effect of hippocampal lesions on recent memory. Trans Am Neurol Assoc 42-48.

Milner B, Squire LR, Kandel ER (1998) Cognitive neuroscience and the study of memory. Neuron 20:445-468.

Napier TC, Chrobak JJ (1992) Evaluations of ventral pallidal dopamine receptor activation in behaving rats. NeuroReport 3:609-611.

Nicola SM, Surmeier J, Malenka RC (2000) Dopaminergic modulation of neuronal excitability in the striatum and nucleus accumbens. Annu Rev Neurosci 23:185-215.

O'Donnell P, Grace AA (1995) Synaptic interactions among excitatory afferents to nucleus accumbens neurons: hippocampal gating of prefrontal cortical input. J Neurosci 15:3622-3639.

O'Donnell P, Greene J, Pabello N, Lewis BL, Grace AA (1999) Modulation of cell firing in the nucleus accumbens. Ann NY Acad Sci 877:157-175.

Olmstead MC, Franklin KBJ (1994) Lesions of the pedunculopontine tegmental nucleus block drug-induced reinforcement but not amphetamineinduced locomotion. Brain Res 638:29-35.

Ou LC, Gean PW (2006) Regulation of amygdala-dependent learning by brain-derived neurotrophic factor is mediated by extracellular signalregulated kinase and phosphatidylinositol-3-kinase. Neuropsychopharmacology 31:287-296.

Parkinson JA, Olmstead MC, Burns LH, Robbins TW, Everitt BJ (1999) Dissociation in effects of lesions of the nucleus accumbens core and shell on appetitive pavlovian approach behavior and the potentiation of conditioned reinforcement and locomotor activity by D-amphetamine. J Neurosci 19:2401-2411.

Paxinos G, Watson C (1998) The rat brain in stereotaxic coordinates. New York: Academic.

Purcell AL, Carew TJ (2003) Tyrosine kinases, synaptic plasticity and memory: insights from vertebrates and invertebrates. Trends Neurosci 26:625-630.

Rademacher DJ, Kovacs B, Shen F, Napier TC, Meredith GE (2006) The neural substrates of amphetamine conditioned place preference: implications for the formation of conditioned stimulus-reward associations. Eur J Neurosci, in press.

Rattiner LM, Davis M, French CT, Ressler KJ (2004) Brain-derived neurotrophic factor and tyrosine kinase receptor B involvement in amygdaladependent fear conditioning. J Neurosci 24:4796-4806.

Robinson TE, Becker JB (1986) Enduring changes in brain and behavior produced by chronic amphetamine administration: a review and evaluation of animal models of amphetamine psychosis. Brain Res 396:157-198.

Robinson TE, Berridge KC (2000) The psychology and neurobiology of addiction: an incentive- sensitization view. Addiction 95 [Suppl 2]:S91-S117.

Robinson TE, Browman KE, Crombag HS, Badiani A (1998) Modulation of the induction or expression of psychostimulant sensitization by the circumstances surrounding drug administration. Neurosci Biobehav Rev 22:347-354.

Scoville WB, Milner B (1957) Loss of recent memory after bilateral hippocampal lesions. J Neurol Neurosurg Psychiatry 20:11-21.

Segal DS, Mandell AJ (1974) Long-term administration of d-amphetamine: Progressive augmentation of motor activity and stereotypy. Pharmacol Biochem Behav 2:249-255. 
Segal DS, Geyer MA, Schuckit MA (1981) Stimulant-induced psychosis: an evaluation of animal methods. Essays Neurochem Neuropharmacol 5:95-129.

Sherman JE, Roberts T, Roskam SE, Holman EW (1980) Temporal properties of the rewarding and aversive effects of amphetamine in rats. Pharmacol Biochem Behav 13:597-599.

Suen PC, Wu K, Levine ES, Mount HT, Xu JL, Lin SY, Black IB (1997) Brain-derived neurotrophic factor rapidly enhances phosphorylation of the postsynaptic N-methyl-D-aspartate receptor subunit 1. Proc Natl Acad Sci USA 94:8191-8195.

Swerdlow NR, Koob GF (1984) Restrained rats learn amphetamineconditioned locomotion, but not place preference. Psychopharmacology 84:163-166.

Tapley P, Lamballe F, Barbacid M (1992) K252a is a selective inhibitor of the tyrosine protein kinase activity of the trk family of oncogenes and neurotrophin receptors. Oncogene 7:371-381.

Thoenen $\mathrm{H}$ (1995) Neurotrophins and neuronal plasticity. Science 270:593-598.

Tyler WJ, Alonso M, Bramham CR, Pozzo-Miller LD (2002) From acquisition to consolidation: on the role of brain-derived neurotrophic factor signaling in hippocampal-dependent learning. Learn Mem 9:224-237.

Vanderschuren LJ, Kalivas PW (2000) Alterations in dopaminergic and glutamatergic transmission in the induction and expression of behavioral sensitization: a critical review of preclinical studies [In Process Citation]. Psychopharmacology (Berl) 151:99-120.

Vezina P, Stewart J (1984) Conditioning and place-specific sensitization of increases in activity induced by morphine in the VTA. Pharmacol Biochem Behav 20:925-934.

Vorel SR, Liu X, Hayes RJ, Spector JA, Gardner EL (2001) Relapse to cocaine-seeking after hippocampal theta burst stimulation. Science 292:1175-1178.

Wang JQ, McGinty JF (1995) Dose-dependent alteration in zif/268 and preprodynorphin mRNA expression induced by amphetamine or methamphetamine in rat forebrain. J Pharmacol Exp Ther 273:909-917.

Winocur G, Rawlins JN, Gray JA (1987) The hippocampus and conditioning to contextual cues. Behav Neurosci 101: 617- 25:742.

Wise RA, Yokel RA, DeWit H (1976) Both positive reinforcement and conditioned aversion from amphetamine and from apomorphine in rats. Science 191:1273-1275.

Yamada K, Mizuno M, Nabeshima T (2002) Role for brain-derived neurotrophic factor in learning and memory. Life Sci 70:735-744.

Yan Q, Radeke MJ, Matheson CR, Talvenheimo J, Welcher AA, Feinstein SC (1997) Immunocytochemical localization of TrkB in the central nervous system of the adult rat. J Comp Neurol 378:135-157.

Zhou W, Mailloux AW, Jung BJ, Edmunds Jr HS, McGinty JF (2004) GABAB receptor stimulation decreases amphetamine-induced behavior and neuropeptide gene expression in the striatum. Brain Res 1004:18-28. 